\title{
Misdiagnosis of gossypiboma as hydatid cyst
}

\author{
Ali Erkan Duman • Osman Ersoy • Osman Abbasoglu • \\ Ozgur Harmanci • Musa Aydinli • Yusuf Bayraktar • \\ Ferhun Balkanci
}

Published online: 22 September 2011

(C) Indian Society of Gastroenterology 2011

A 51-year-old woman was admitted for diabetes control. She was found to have a firm, mobile, large epigastric mass during physical examination. Laboratory findings were within normal range. She had undergone cholecystectomy at another hospital 8 years ago.

On computerized tomography (CT) of abdomen showed a large intra-abdominal cystic mass measuring $102 \mathrm{~cm} \times$ $106 \mathrm{~cm} \times 181 \mathrm{~cm}$, originating from duodenopyloric junction, which compressed duodenum and pylorus. The appearance of the mass was consistent with type II hydatid cyst (Fig. 1). The patient was advised albendazole therapy; 2 months later, the cyst was treated by puncture, aspiration, injection of a helminthicide, and reaspiration (PAIR) technique. Analysis of cystic fluid was not consistent with hydatid cyst.

A post-treatment CT scan showed a reduced size of the cyst; however it returned to its original size within 3 months after treatment. The patient underwent a diagnostic laparotomy which detected four sponges within the cyst (Fig. 2).

\footnotetext{
A. E. Duman

Faculty of Medicine, Department of Internal Medicine,
}

Hacettepe University, Ankara, Turkey

O. Ersoy $\cdot$ O. Harmanci · M. Aydinli · Y. Bayraktar Faculty of Medicine, Department of Gastroenterology,

Hacettepe University, Ankara, Turkey

\section{O. Abbasoglu}

Faculty of Medicine, Department of General Surgery,

Hacettepe University, Ankara, Turkey

\section{F. Balkanci}

Faculty of Medicine, Department of Radiology,

Hacettepe University, Ankara, Turkey

\section{A. E. Duman $(\bowtie)$}

Department of Gastroenterology,

Kocaeli University Medical Faculty Hospital,

Eski Istanbul yolu 10. Km,

41000 Kocaeli, Turkey

e-mail: dralierkanduman@hotmail.com

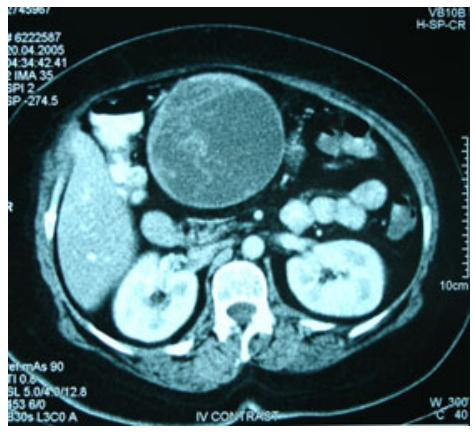

Fig. 1 Computerized tomography of abdomen showing a large intraabdominal cystic mass

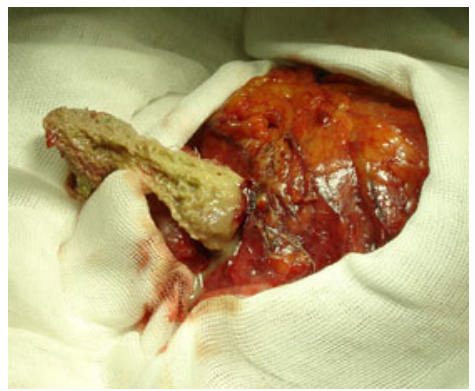

Fig. 2 Appearance of sponges during laparotomy

Sponges used during surgical operations are occasionally left in abdominal cavity accidentally. The amount of actual occurrences is possibly more than what are reported [1]. Retained intra-abdominal sponges have been misdiagnosed preoperatively as lymphosarcoma, bowel tumor, tuberculosis, and ovarian tumor [2]. There has not been a misdiagnosis of a gossypiboma as hydatid cyst earlier.

\section{References}

1. Kaiser CW, Friedman S, Spurling KP, et al. The retained surgical sponge. Ann Surg. 1996;224:79-84.

2. Rajagopal A, Martin J. Gossypiboma - “a surgeon's legacy": report of a case and review of the literature. Dis Colon Rectum. 2002;45:119-20. 